\title{
New Strategies of Linkography for Investigating the Role of Dialogues in Architectural Design Education
}

\author{
${ }^{1}$ Nessma Amin Al-Hammadi and ${ }^{2, * *}$ Dr. Saleem Mokbel Dahabreh, PhD \\ ${ }^{3}$ Dr. Ma'en Abdel-Jaber, PhD \\ ${ }^{1,2}$ University of Jordan, Queen Rania str., Amman, Jordan. \\ ${ }^{3}$ Applied Science Private University, Al Arab St 21, Amman, Jordan.
}

\begin{abstract}
Design takes the form of verbal and visual negotiation among designers, designers and clients, and students and instructors. This raises the question of the role of verbal dialogue in the production of architectural designs. Through protocol analysis of the interaction of instructor-student in two fifth-year graduation projects over the course of two semesters, this paper emphasizes the crucial role of 'dialogue' in the reformulating of a design situation, enabling the simultaneous investigation of theory, form, architectural language, and building type, where theory proved to be a decisive factor, and opening up venues of creative thinking.".
\end{abstract}

Kewords: Design evolvment, dialogue, protocol analysis

\section{INTRODUCTION}

The nature of the architectural design as a prospective enterprise and the complexity of information and activities involved necessitates the engagement of two types of representations: visual/formal and verbal/conceptual (Shih, 2004). Verbal expressions allude themselves into architectural discussions where words help designers express, communicate, and explain their ideas to others, which is essential in the design process (Poggenpohl, Chayutsahakij \& Jeamsinkul, 2004). Particularly in design studios, students are often asked to talk about their concepts and designs whether in discussions with tutors or during design reviews. Tutors and instructors reflect and critic designs verbally, which sets verbal language as an important tool used by students and instructors for communicating information (Avidan and Goldschmidt, 2013).

This type of verbal interactions and negotiations back and forth especially between design instructors and their students institutes a form of dialogue that is an essential part of collaborative practice and occurs in tandem with the modes mentioned above of representation (Oak, 2011). Subsequently, architectural design proceeds through the dialogue between involved design parties and verbal expressions and visual representations and reaches its final form synergistically.

This paper addresses the role of dialogue in design evolvement in design studios. The importance of the interaction of verbal and visual representations in design is supported much in design related literature: Lawson and Loke (1997) argued that creative design is dependent on words as much as on images. According to Tomes Oates, and Armstrong (1998), verbally formulated core concepts are essential in focusing the work of design teams and communication between designers and their clients. For Tomes, Oates, and Armstrong (1998) the ability to articulate verbal meanings associated with visual design, and to interpret verbal messages in visual terms is a core skill in producing a creative design. While discussing objectives of design education, Ulusoy (1998) argued that the verbal faculties and expressions of students and instructors are influential on the process of designing especially with regard to understanding, criticizing and evaluating designs. For Dong (2007), the verbal language in design is less of linguistic descriptions and more of the generative mean of design generation and production.

The present study uses protocol analysis of two fifth year graduation projects from the University of Jordan over the duration of two semesters (1915-1916) to understand the role of 'instructor-student' dialogue in form generation and shifting design focus to advance creativity. The research methodology adopted Dahabreh's (2014) 4f_C framework to theory, form, formal language, and building type terminology and used them as segments within Kan and Gero (2008) linkograph procedures that was based on Goldschmidt (1992, 2014) work. Gabriela Goldschmidt $(1992,2014)$ presents linkography as a method for the notation and analysis of the design process through the generation of distinctive interlinks between design moves and ideas that transform the design process. As such, linkography, particularly with Kan and Gero proposed strategies, documents how designers think, generate ideas, put them to the test, and combine them into something meaningful. The findings of the present study conformed with previous studies about the crucial role of 'Dialogue' in design framing and reformulation. It further confirmed the cyclic nature of the design process as an endless parallel loop of reflection in, on, and for action, which provides the ability of holistic investigation of various design aspects; theory, form, architectural language, and building type. In addition, the adopted methodology has enabled the investigation of design categories (theory, form, architectural language, and building type) where the dominant role of theory was crucially dominant. Consequently, the study conflicted the tradition teaching approaches which will assist the enhancement of design studios' teaching methods.

\section{Architectural Design and Dialogue}

The synthetic spatial and physical nature of architectural design

\footnotetext{
* Corresponding Author
} 
requires the use of visual representations to externalize abstract concepts and formalize designs. Nevertheless, visual representations are not sufficient in communicating all aspects related to a design to others, especially that they can be easily misunderstood or misinterpreted particularly in the preliminary sketching phase while not supported with words and their strength of articulation (Hergeršič, Pungerčar, and Zupančič, 2013). Consequently, designers incorporate language to fully express, and present their ideas and designs to other designers, clients, the public and media (Shih, 2004). This is especially true in design studios when students are asked to present their ideas and tutors reflect and critic designs verbally while considering students visual representations. The intertwinement of visual and verbal during the critical moments of the design process is of key importance for effective design experience. (Cikis and Ek, 2015). Once visual representations and verbal expressions materialize abstract design ideas and render them perceptual to designers and others, they open them up for possible reflection (Birkhäuser, 2007). In that sense, the reflection on architectural design could be perceived as a communicative activity (Perry and Sanderson, 1998). The communicative activity can be seen more of a 'dialogue' and less of a 'debate' or 'discussion' (Romney, 2005). Accordingly, the design process itself is considered a dialogical conversation between seeing 'that' and the seeing 'as' amongst the designer himself/herself, the visual representation, and others involved (Lawson, 1994, 2006).

Dialogues with their inherent feedback loops construct knowledge; they bring together the observations and understandings of different people in the pursuit of common projects (Schaik, 2014). According to Isaacs (1999), dialogue comes from the root Greek word 'dialogues' where Dia means 'through'; logos translates to 'word' or 'meaning.' Thus, the literal meaning of dialogue is a 'flow of meaning.' Furthermore, ' $\log o s$ ' as 'word' was also used in ancient Greek in the broader sense of speaking, thinking, reckoning, reasoning, etc., accordingly 'logos' was used in the much broader sense of reasoning of any kind expressed through speaking or writing and retained in the form of a concept or a theory. All accounts of dialogue can be traced back to Socrates' dialogues (Ravenscroft, Wegerif, and Hartley, 2006). Plato's dialogues are examples of the Socratic Method, which is a form of educational dialogue in which a student's knowledge is brought forth by expert questioning of the teacher (Romney, 2005). The basic premise behind the use of dialogue is that knowledge can be acquired via logical inquiry through the dialectic between a student and a teacher. Dialogue in this case of architectural design is exploratory, to use Bohm's (2013) term, aiming at exploring not only design/s but also underlying presuppositions, ideas, and beliefs. In the case of design instruction, or 'institutional talk', Dialogue can be identied as a focused conversation, engaged in intentionally with the purpose of increasing understanding of what the designer has done, addressing issues that arise while designing, and questioning thoughts or actions (Arminen, 2005). It becomes a shared cooperative enquiry, a way of thinking and reflecting between student/s and instructor about a design project with space to challenge, question, appeal to reason, thus, allowing possible re-correction and development (Fisher, 2007).

This process of backtalk is a reflective process where both student and instructor reflect-on what has been done and reflect-for future action. Reflection-on is both descriptive and exploratory in nature, aiming to provide insight into the past and answering: "What has been done?"; explanatory answering the questions of "How the design came about?" and "Why it came about this way?" (Schön, 1984). Reflection-for-action was proposed by Killion and Todnem (1991) to guide the more practical future action by identifying constructive measures to further develop and procced. Talking about an a proposed architectural design in a studio is not an easy task; as a phenomenon, architectural design is characterized by complexity and linked to multiple bodies of knowledge belonging to diverse disciplines. As such, reasoning about an architectural design through dialogue addresses many issues (Dahabreh, 2014b). To better undestand the 'instructor-student' dialogue, this study uses a protocol analysis of two graduation projects from the University of Jordan over the duration of two semesters. The research methodology adopted Suwa and Tversky (1997) theory, form, formal language, and building type terminology and used them as segments within Kan and Gero (2008) linkography procedures that were based on Goldschmidt $(1992,2014)$ work.

\section{METHODOLOGY}

This study applied an in-depth investigation of two fifth year Graduation projects (Project A and B), where each project was designed by two students at the University of Jordan over two semesters i.e. eight months. The study took place at the office and studios of the university during both formal and informal meetings at the instructors' office. The projects were selected because both of them were among the top three winners in two regional competitions. The meetings were not structured beforehand, and the researcher only monitored the instruction and observed and recorded the dialogues. The recordings took the form of notes and audio taping to observe and analyze ideas evolvement and restructuring. The chosen projects addressed different architectural concerns. Project A addressed industrialresidential sprawl clashing and applied a systemic growth for the industrial- residential areas by a symbiotic zone that ensures the coexisting of the two forces. Project B addressed random urbanization and addressed it through a deformed structural geometry that acts as a mediator (a Parasite) to existed buildings to symbolize architectural social evolving neglecting.

In order to interpret the data, the first step was to determine a set of information categories into which the contents of participants' protocols could be fit. These categories are: theory, form, formal language, building type. These correspond to Dahabreh's (1914) 4F_C framework. In the framework, formative Idea (FI) represents the theory (t) part of the design. Spatial form refers to the functional building type of the project (BT). Intellectual form (IF) represents the formal language (FL) component including geometry and architectonics. Structural form (SF) referred to the materiality (M) of the proposed design.

The paper adopted 'linkography' as a protocol analysis method. This method was first conducted by Gabriela Goldschmidt $(1992,2014)$ who proposed it as an analysis technique for the design process to comprehend design moves' interlinks and characteristics. The recorded dialogues mainly addressed 
verbal tasks since the visuals, i.e. drawings, were not included. Thus, verbal dialogues were the main data source while the visual ones were the secondary (as a confirmation of the effective ideas in the design process) (see Appendix A).

The recordings followed Barak's (2006) three dialogue phases: 'parallel dialogue' to identify thoughts for improving decisionmaking abilities, 'divergent dialogue' to explore and connect ideas through practices in which certain comments trigger different ideas, and 'convergent dialogue' to converge the collected understandings for generating an appropriate design. However, since "there is no natural end to the design process" (Lawson, 2006, p.55), dialogues keep repeating the cycle in an endless loop until they generate a balanced work.

The study constructed the analysis criteria of meanings and actions' interpretations through following the Suwa and Tversky (1997) study that analyzed the verbal task for 'Conceptual Dependency' through three different steps: segments encoding that divide encoded protocols into logical statements; subclasses encoding to categorize verbal protocols into subclasses by subjective justification; and, conceptual dependency analysis (CD) for elaborating the segments' connections to the previous ones. Therefore, forming a 'chunk' or a 'block' of a group of segments to reflect the logical design thinking which defined it with ten design moves (segments) only according to Suwa and Tversky (1997). Consequently, the present study depended mainly on Suwa and Tversky (1997) study model with the use of Goldschmidt (1992, 2014) linkography concept for segments estimation and observation. The study further incorporated Kan and Gero (2008) two methodological strategies of cluster analysis and statistical descriptions to classify linkography into significant clusters and meaningful abstract data of design procedures. In this sense, the paper analyzed the projects' lithographs within the mentioned strategies to determine the impact of design categories (Theory, Form, Architectural Language, and Building Type).

\section{Data Analysis}

\section{- Study Protocol analysis}

\section{Phase One: 'Conceptual dependency' Analysis}

Once the collected data was compiled, it was analyzed with three phases:

1) Verbal protocol encoding segments where segments which played a significant role in design development were extracted logically; due to its semantic, pragmatic features, and their impact on the design process.

2) Segments quantity and classification by investigating the circulation of segments categories through the design process.

3) Sequentially conception which estimates the Conceptual Dependency (CD); according to Suwa and Tversky (1997) study, to describe the design idea association with previous ctegories by determining several terms:

a) Segments' Interlinks: Explore backward and forward segments' links to define the 'Focus-shift segments' (every first segment that shifts the focus from one 'block' to another), and
'Continuing segments' (sequential segments that associate the 'block' in meaning and form).

b) Segments' Relations: Define the 'Dependency chunks' to represent the interlinked segments in each 'block' that contains a focus-shift segment and the continued ones, and 'Dependency links' to examine interlinks between segments of different blocks.

c) Conceptual Dependency (CD): It emerges among continuing segments which have previous interlinks with other segments; therefore, focus shift segments do not have CD since they shift the connection from a block to another.

\section{Phase two: 'Critical design moves' analyses}

Following the work of Kan and Gero (2008), the study investigated Interlinks pattern and their conceptual, statistical descriptions. Design categories interlinks' pattern and effect on design process were investigated first by determining link's types and behaviors (orientations and amounts). In this sense, the study identified 'Backlinks' that connect design moves to previous categories and 'Forelinks' that connect them to forward ones. Then, conceptual, statistical descriptions of linkography were studied by neglecting the linking lines and considers only the nodes as points on the (X, Y) dimensions. For this, the analysis estimated the means and the standard deviations conceptually by analyzing nodes' concentration average location among $\mathrm{X}$ and $\mathrm{Y}$ coordinates to investigate the impact of each design aspect.

\section{DATA RESULTS AND DISCUSSION}

Verbal protocol encoding segments in phase one analyzed the row verbal data in each design session dialogue i.e., words, phrases, and sentences in project A (Figure, 4.1) and project B (Figure, 4.2). Accordingly, the encoding extracted effective segments that played a considerable role in chanelling design progress and results by focus-shifting within design categories. This ultimately represents the role of dialogue in either reformulating existing ideas or generating new ones constantly. The analysis of segments subclasses and quantity emphasized that design thinking is non-sequential, loop and parallel, which elaborated that ideas were not generated through a stable pattern, but dialogical thinking guided them in each meeting. Furthermore, the Conceptual Dependency (CD) analysis highlighted that by merging similar ideas within the same category, a condensed conclusion would be created to define segments' characteristics in types; focus-shift segments and continuing segments, and in relations; dependency chunk and dependency links. Focus-shift segment, i.e. the first segment, creates a 'block' of ideas and shifts the focus from one to another, while the remaining segments are the continuing ones. Nevertheless, due to the project nature, each focus-shift segment indicates the role of design dialogue in clarifying each design process and generating design solution by either one idea or a set of previously analyzed ideas. These results, are consistent with Suwa and Tversky (1997) results which show that once architects shift their focus of attention, they think more deeply about the topic been discussed. This partially due 
International Journal of Engineering Research and Technology. ISSN 0974-3154, Volume 13, Number 6 (2020), pp. 1391-1408

(C) International Research Publication House. https://dx.doi.org/10.37624/IJERT/13.6.2020.1391-1408

to the fact that designer architects are able to 'read-off' more different types of information from their drawings and sketches.

In every project, CD might be increased by expanding ideas' analysis which would generate both types of segments. With dependency relations, 'Dependency Chunks' are clarified as segments' with internal relations that connect a focus-shift segment with continuing ones in each block which reflected that students spend more time in analyzing certain ideas within different phases during the design process. As such, dependency chunks and segments' variations in design categories underlined the importance of investigating each idea through various design aspects, and enable a better design problem understanding that leads to a better design solution generation.

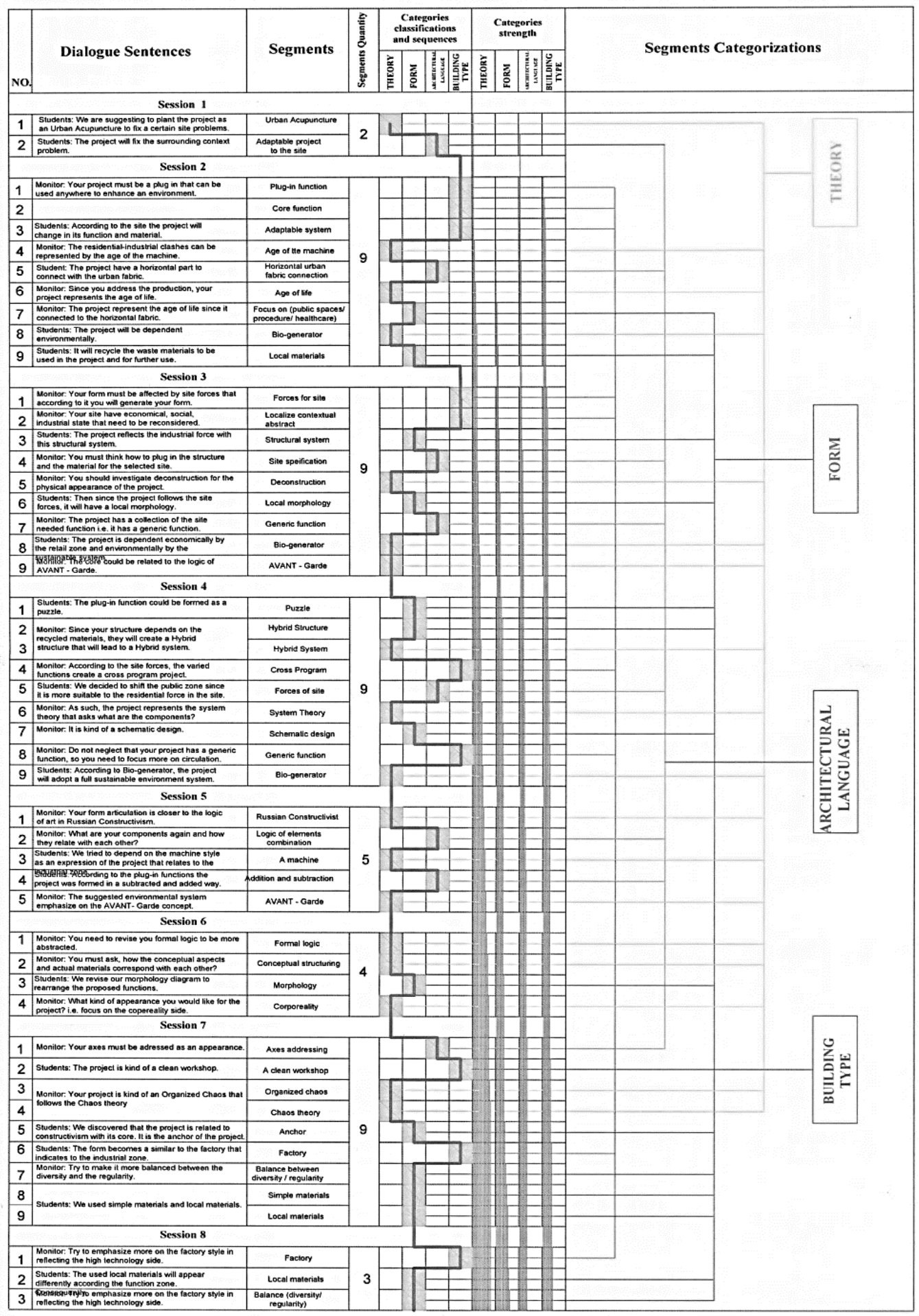

Figure (4.1): Verbal protocol encoding segments of Project A (Source: Drawn by the author) 
International Journal of Engineering Research and Technology. ISSN 0974-3154, Volume 13, Number 6 (2020), pp. 1391-1408

(C) International Research Publication House. https://dx.doi.org/10.37624/IJERT/13.6.2020.1391-1408

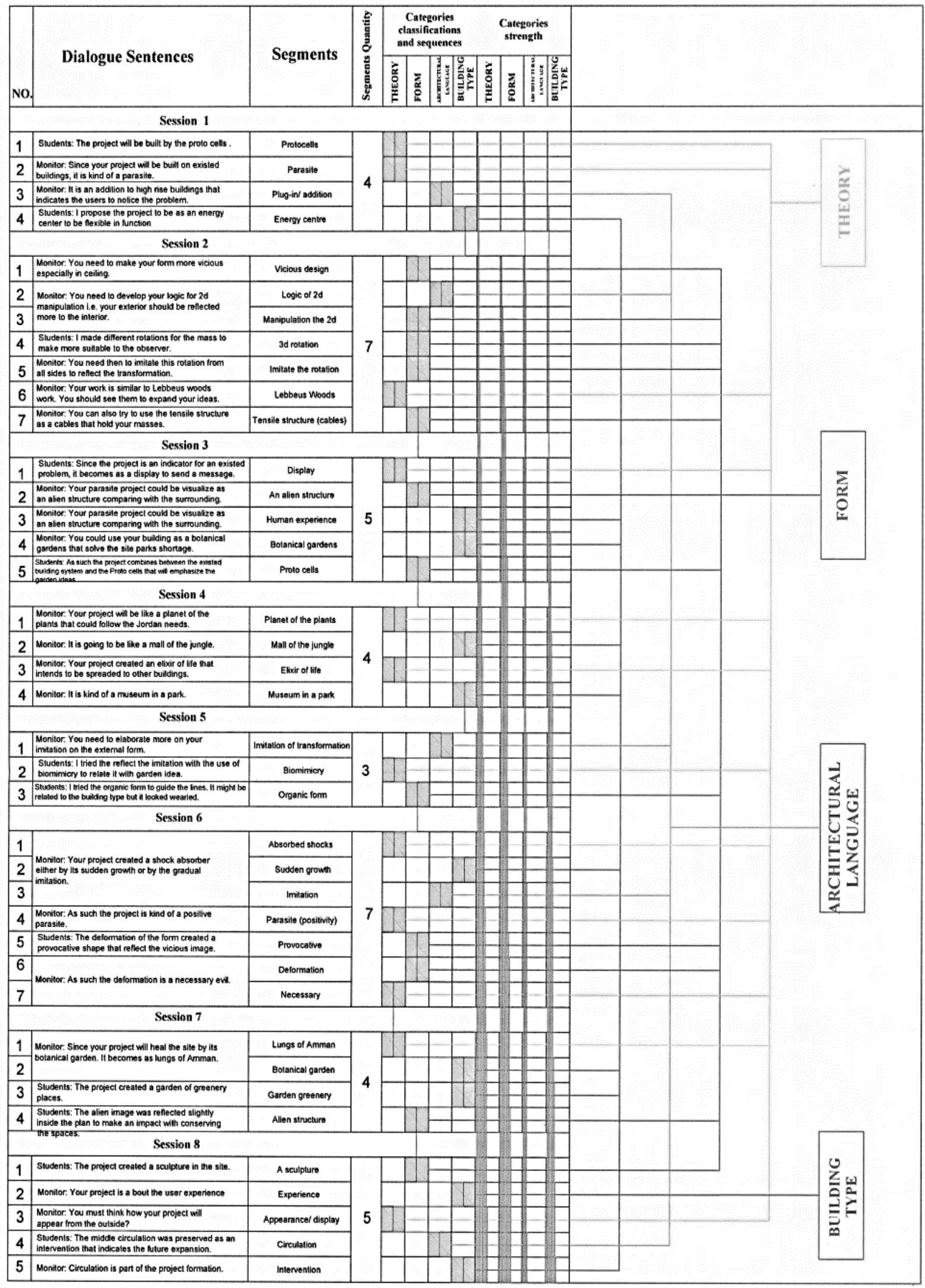

Figure (4.2): Verbal protocol encoding segments of Project B

(Source: Drawn by the author) 
As such, CD represents the students' analyzing phase where they widen their thinking within a certain idea until they reach the idea that shifts the design process to another level. By comparing the CD level in both projects (Figure, 4.3), project A showed more $C D$ which indicates that students in project $A$ spent more time in expanding their ideas' analysis.

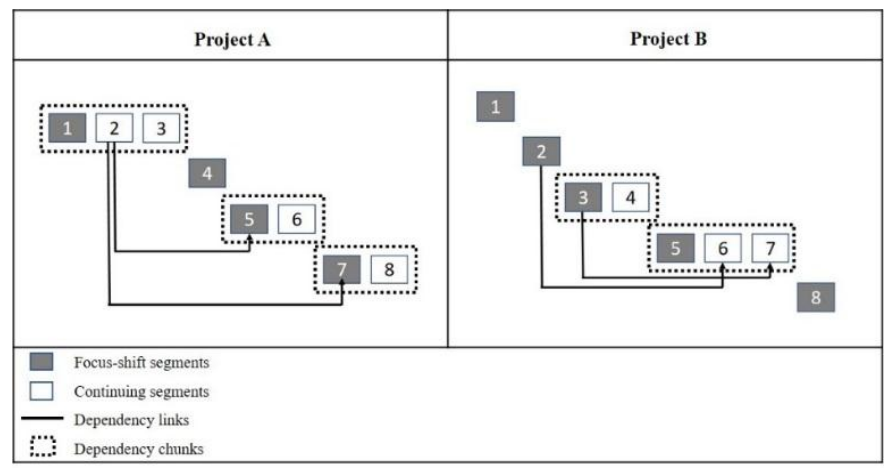

Figure 4.3: Conceptual schematic graphs of conceptual dependency segments

(Source: Redrawn by the author after Suwa and Tversky (1997))

On the other hand, 'Critical design moves' were analyzed in phase two by examining the design categories patterns with a conceptual schematic graph for representing the categories linkages' orientations (Figure, 4.4) and strengths (Figure, 4.5) to investigate the categories impact during the design process.
Moreover, as a theory in project $\mathbf{A}$ and $\mathbf{B}$ had the highest concentration of linkages (Figure, 4.4), the significant effect of theory on both design procedures is emphasized. Accordingly, theory considers the anchor that linked all design aspects and ultimately controlled the designing process.

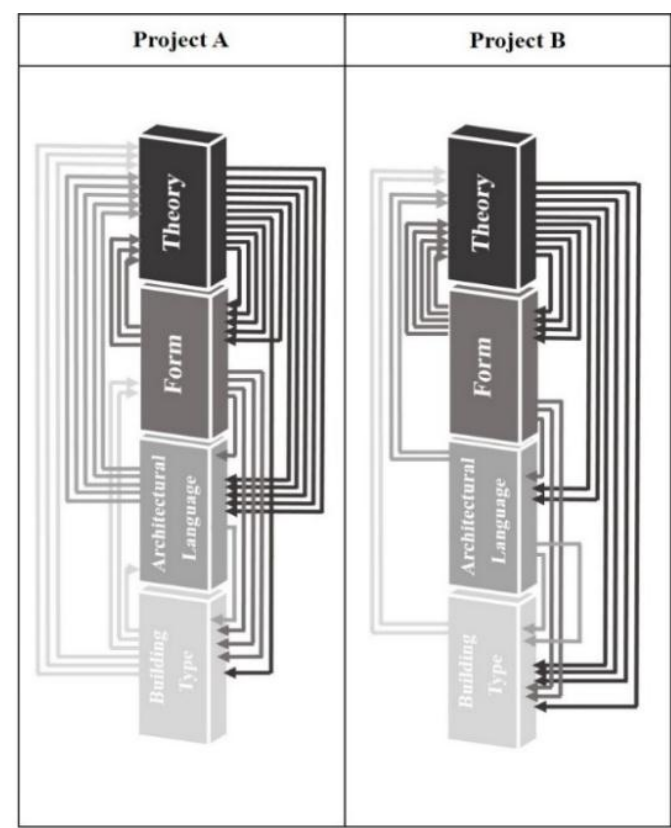

Figure 4.4: Conceptual schematic graphs of categories linkages' orientations

(Source: Drawn by the author)

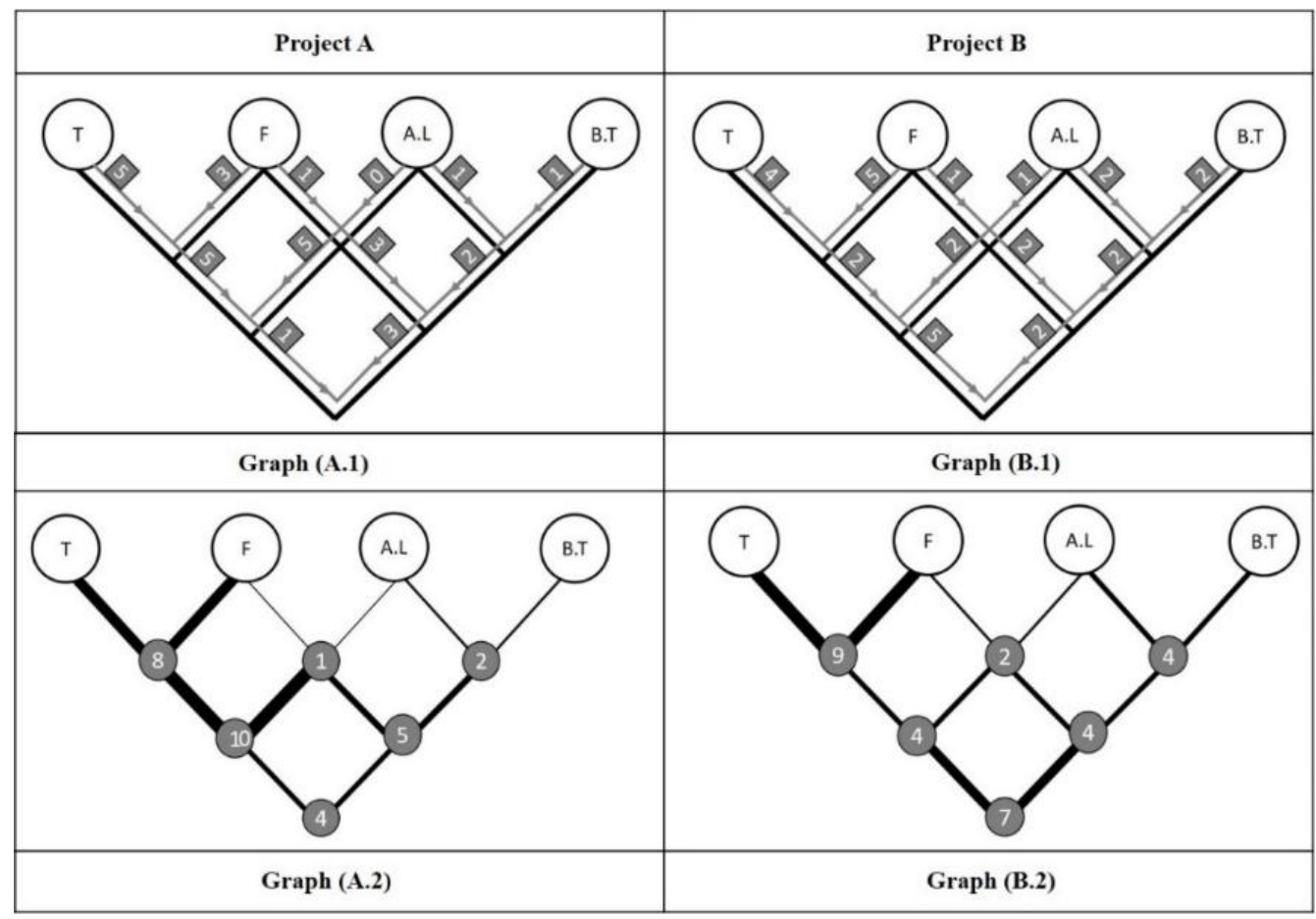

Figure 4.5: Conceptual graphs of categories linkages' analysis

(Source: Redrawn by the author after Kan and Gero (2008)) 
Conceptual and statistical descriptions linkographs of project $\mathrm{A}$ (Figures, 4.6: 4.7) and project B (Figures, 4.8:4.9) represent the linkographs of theory, form, architectural language, and building type. These figures analyze the location of the nodes' concentration average along the $(\mathrm{X}, \mathrm{Y})$ dimensions to define the impact of each category among the design process. The extensive theory links and nodes in both projects emphasized the dominant role of this category in the designing decisions along the design process. Form links and nodes show their main impact on the middle of the design process in the project (A), while in the middle and the end of the project (B). The architectural language aspects were more effective in the project (A) than in project (B); however, the related links and nodes were more concentrated in the first half of the design process in both projects. Building type considerations were also equivalent in both projects comparing with the other categories by affecting the later stage of the designing procedure. Moreover, it is worth mentioning that linkography nodes along the $\mathrm{Y}$-axis created long links range in all the design categories except the Architectural language which had shorter links in both projects due to its earlier effect on the design process.
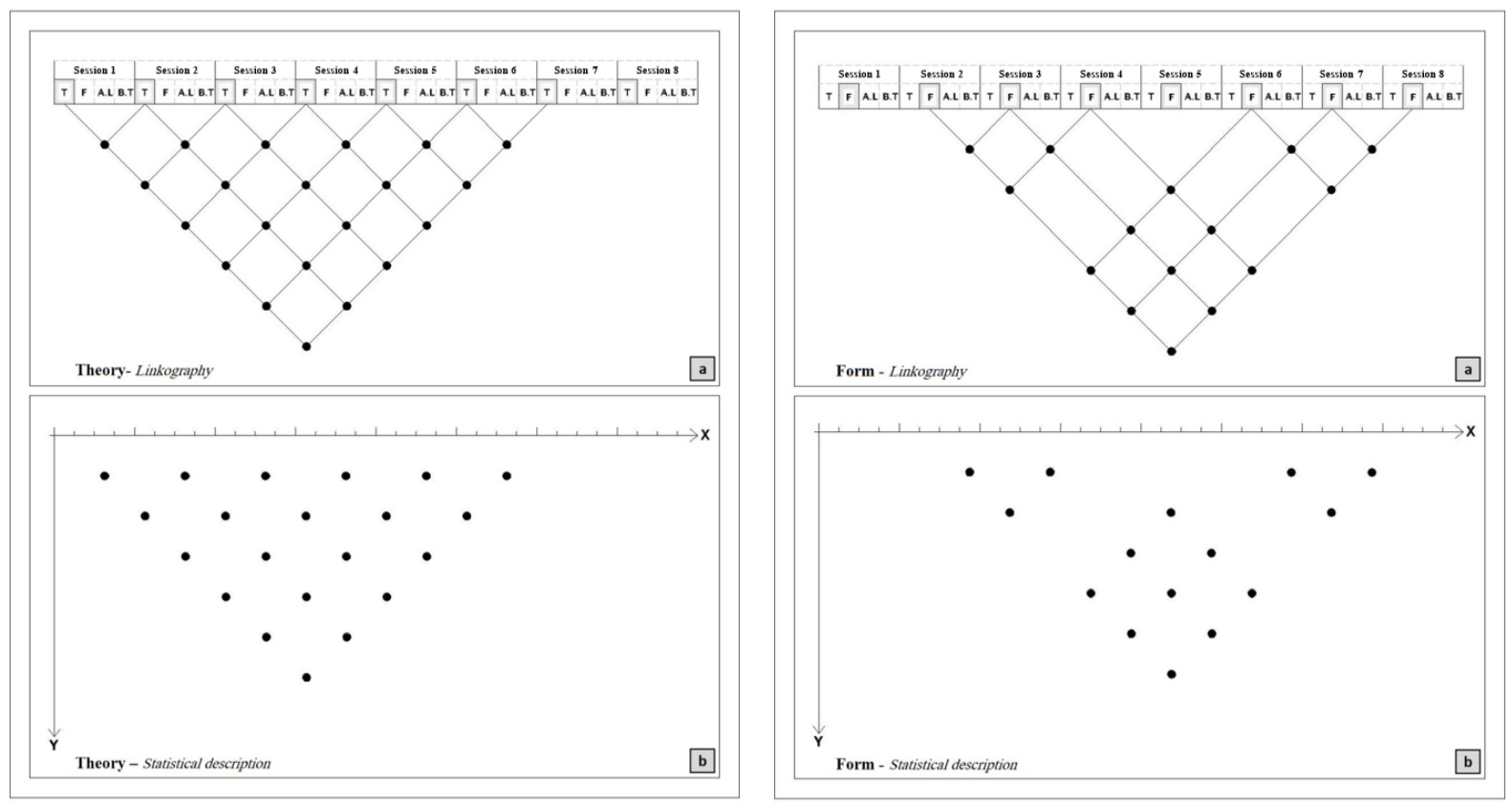

Figure 4.6: Project (A-Theory/ Form) linkographs and their conceptual statistical description (Source: Redrawn by the author after Kan and Gero (2008))
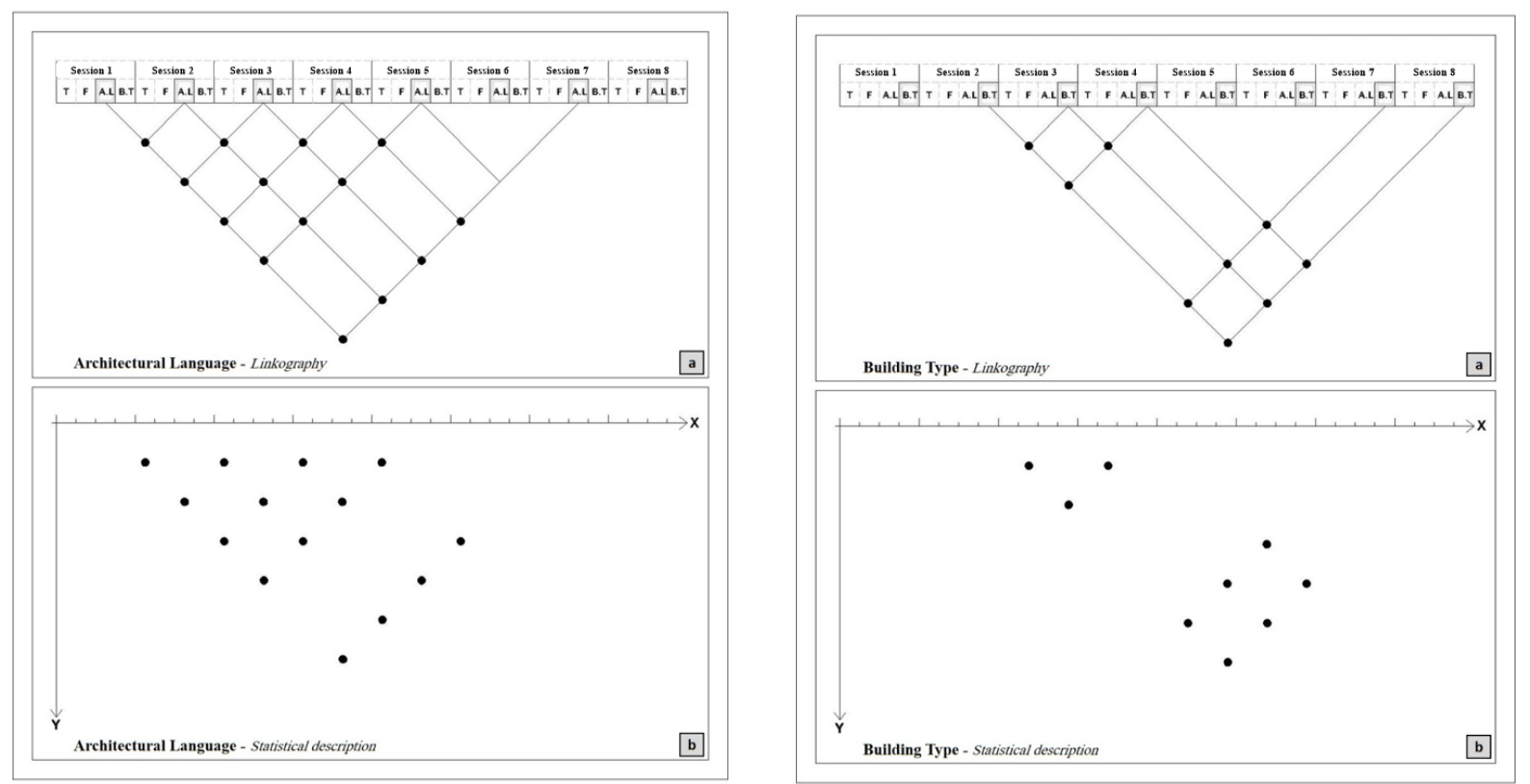

Figure 4.7: Project (A-Architectural language/ Building Type) linkographs and their conceptual statistical description (Source: Redrawn by the author after Kan and Gero (2008)) 
International Journal of Engineering Research and Technology. ISSN 0974-3154, Volume 13, Number 6 (2020), pp. 1391-1408

(C) International Research Publication House. https://dx.doi.org/10.37624/IJERT/13.6.2020.1391-1408
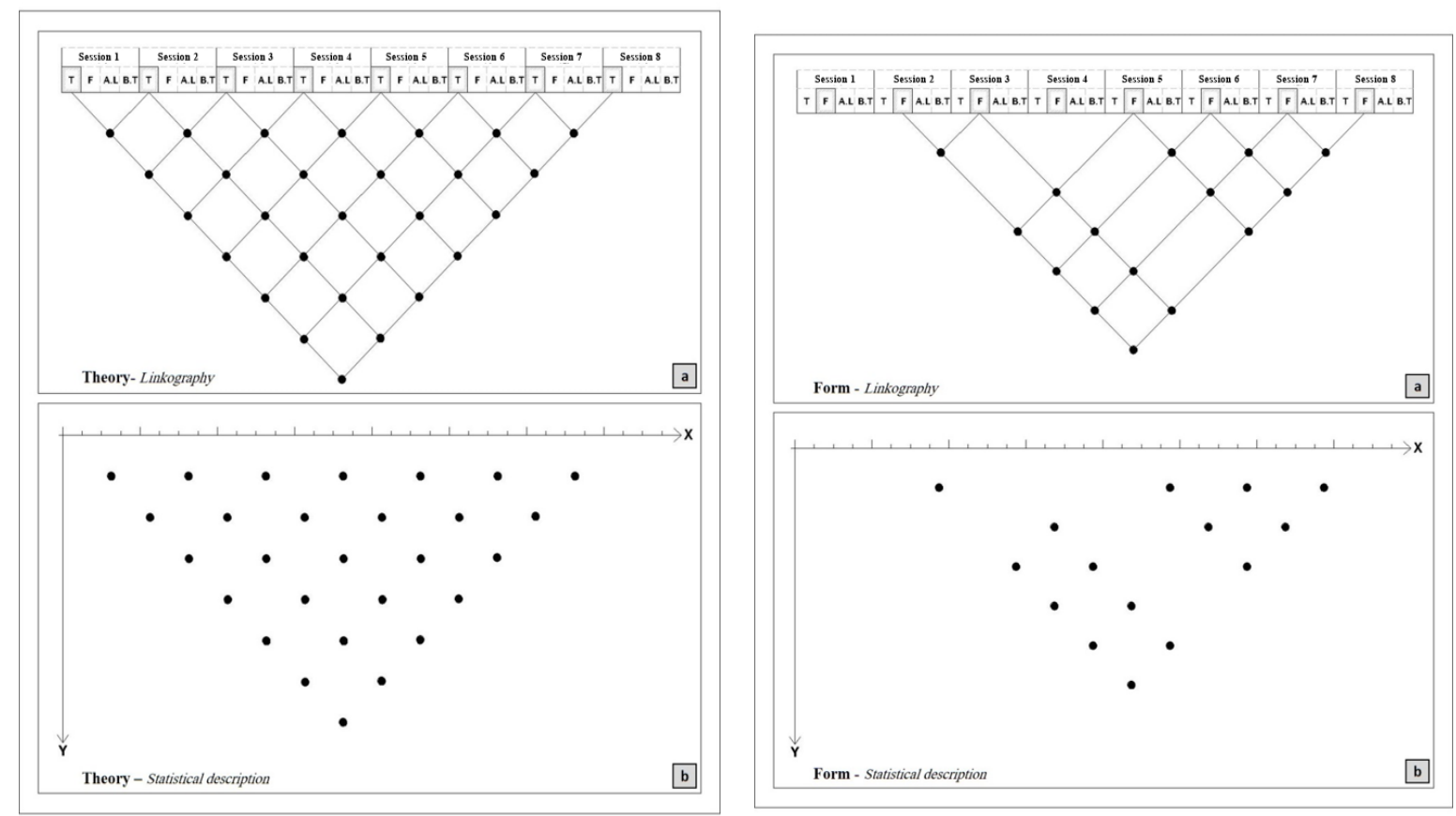

Figure 4.8: Project (B-Theory/ Form) linkographs and their conceptual statistical description (Source: Redrawn by the author after Kan and Gero (2008))
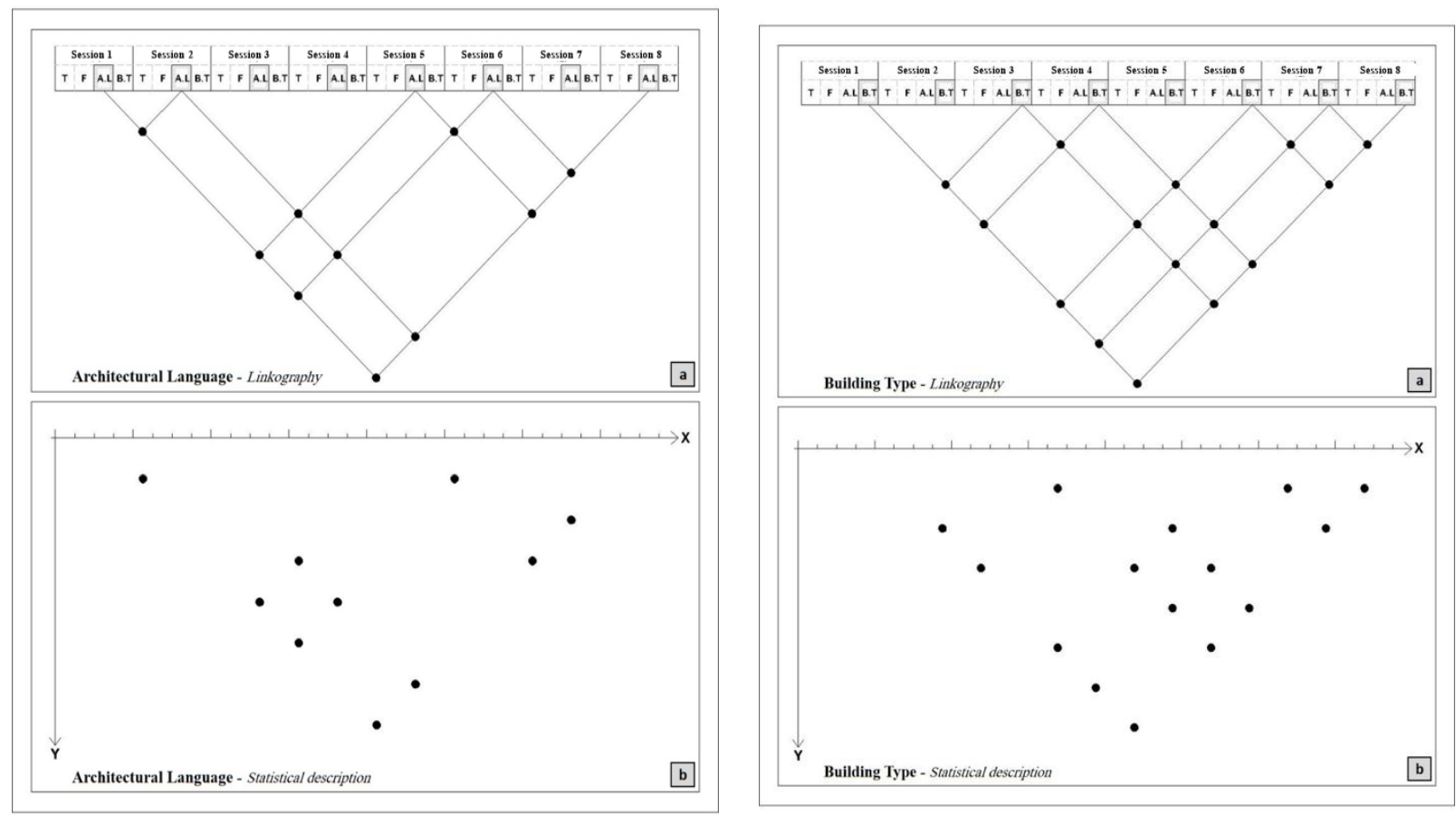

Figure 4.9: Project (B-Architectural language/ Building type) linkograph and their conceptual statistical description (Source: Redrawn by the author after Kan and Gero (2008))

\section{CONCLUSIONS}

Architectural design is an integrative and interdisciplinary process with complex requirements. Emanating from the scope and complexity of architectural design is the need for visual/formal representations and verbal/conceptual expressions. Although the visual/non-verbal communication is the key communication mode in the design studio and practice, the intertwinement of visual and verbal communication in a dialogue between students and instructors during the critical moments of the design process is of key importance for effective design education. Dialogue as a verbal interchange of 
thoughts, opinions, and reflections between two or more persons about a variety of artefacts and design tools creates a learning environment where participants do design in ways that enable the emergence of mutually understood meanings, and new, innovative designs.

Dialogue had a great impact in the early phases of design where students seek to generate many diverse, not previously recognized options and explore their validity. Thus, dialogue becomes essential for emergence and reinterpretation of ideas during the design process; emergence refers to new thoughts and ideas that could not be anticipated or planned before the dialogue and reinterpretation refer to the ability to transform, develop and generate new images in the mind while discussing presented proposals. This agrees with Dong's (2007) view where reinterpretation refers to the ability to transform, develop and generate new images in mind through using a design language, which enacts design aggregation and blending of ideas and concepts; accumulation to scaffold ideas and concepts; and appraisal to evaluate and assess language use in design. As such, dialogue' can be utilized as means to enhance ideas since it can be used to develop the awareness, to control the mental processes and to improve the conceptual thinking tools.

Dialogue and sharing ideas with instructors and other students challenges and motivates students to express their ideas, overcome an initial psychological threshold, as well as strengthen their opinion, self-criticism and argument techniques. Through dialogue, it becomes easier for them to identify key critical issues in the design and reflect upon transforming their tacit knowledge about design into the explicit knowledge mode. Thus, through dialogue, students are encouraged to improve the design efficiency and to explore new potentials.

Another contribution of the present research is the investigation of the categories of theory, form, architectural language, and building type as characteristic focus-shift segments and continuing segments in the design process. During design sessions, the research showed that at least two categories were always discussed during sessions where some words or phrases have triggered new ideas that either moved forward or went backward for further investigation. This demonstrates the parallel and looping nature of the design process that enables the holistic awareness of design problems rather than the linear nature traditionally employed in design studios.

Due to the projects variation in nature, design processes linkography were also varied. Nevertheless, in both projects, Theory played the dominant role in the designing procedure with strong linkage to Form, while the latter main impact was concentrated on the middle. The early stages of both projects' design process were affected by Architectural language considerations. In contrast, Building type aspects influence was during the later stages. In addition, the findings highlighted the long linkages range of design categories except for the Architectural language for its early impact on design decisions.

In summary, this paper has demonstrated how deeply collaborative, contingent, contextually-specific, and discursive is design practice, as it is performed in settings that require participants to clarify, explain, interpret, assess, argue, and engage in iterative levels of reflection and critique.

\section{REFERENCES}

[1] Arminen, I. 2005. Institutional Interaactions: Studies of Talk at Work. Ashgate Publishing Limited. Aldershot

[2] Avidan, Y., and Gabriela Goldschmidt, G. (2013). Talking Architecture: Language and Its Roles in the Architectural Design Process. In A. Chakrabarti and R. V. Prakash (eds.), ICoRD'13, Lecture Notes in Mechanical Engineering

[3] Barak, O. L. (2006). Convergent, divergent and parallel dialogues: knowledge construction in professional conversations. Teachers and Teaching: theory and practice, 12(1), 13-31.

[4] Bohm, D. (2013). On dialogue. Routledge

[5] Bohm, D., Factor, D., \& Garrett, P. (1991). Dialogue: A proposal. The informal education archives. Online im Internet: URL: http://www. infed. org [Stand: November 2004].

[6] Christiaans, H. H. C. M. (1992). Creativity in design: the role of domain knowledge in designing. TU Delft, Delft University of Technology.

[7] Cikis, s., Ipek Ek, F. (2010) Conceptualization by Visual and Verbal Representations: An Experience in an Architectural Design Studio, The Design Journal, 13:3, 329-354

[8] Dahabreh, S. (2014), 4f_C: A conceptual framework for understanding architectural works, Academic Journals, Scientific Research and Essays, Department of Architecture, Faculty of Engineering and Technology, University of Jordan, Amman.

[9] Dong, A. (2007). The enactment of design through language. Design Studies 28 (2007) 5-21

[10] Fisher, R. (2007). Dialogic teaching: developing thinking and metacognition through philosophical discussion, Early Child Development, and Care, Brunel University, Uxbridge, UK, Taylor \& Francis.

[11] Gänshirt, C. (2007). Tools for ideas: Introduction to architectural design. Walter de Gruyter.

[12] Genzuk, M. (2003). A Synthesis of Ethnographic Research, PH.D., University of Southern California, Center for Multilingual, Multicultural Research.

[13] Goldschmidt, G. (1991). The dialectics of sketching. Creativity research journal, 4(2), 123-143.

[14] Goldschmidt, G. (1992). Criteria for design evaluation: a process-oriented paradigm. Evaluating and predicting design performance, 67-79.

[15] Goldschmidt, G. (1995). The designer as a team of one. Design Studies, 16(2), 189-209.

[16] Goldschmidt, G. (1998). Creative architectural design: reference versus precedence. Journal of Architectural and Planning Research, 258-270.

[17] Goldschmidt, G. (2014). Linkography: unfolding the 
design process [Kindle Edition]. The MIT Press eBooks.

[18] Hergeršič, A. K., Pungerčar, E., Zupančič, T. (2013). Non-Verbal Communication in Collaborative Architectural Design. In Computation and Performance - Proceedings of the 31st eCAADe Conference, 243252. Delft, The Netherlands: Delft University of Technology, 2013.

[19] Isaacs, W. 1999. Dialogue: The Art of Thinking Together. 1st edition Currency Hardcover - September 14, 1999

[20] Kan, J. W., \& Gero, J. S. (2008). Acquiring information from linkography in protocol studies of designing. Design Studies, 29(4), 315-337.

[21] Killion, J., \& Todnem, G. (1991). A process for personal theory building. Educational Leadership, 48(6), 14-16.

[22] Lawson, B. (1994). Design in mind. Architectural Press.

[23] Lawson, B. (2006). How designers think: The design process demystified. Routledge, 3rd.

[24] Lawson, B., Loke, S. M. 1997. Computers, words and pictures. In Design Studies 18(2):171-183

[25] Oak, A., (2011). What can talk tell us about design? Analyzing conversation to understand Practice. Design Studies 32, 211-234

[26] Perry, M. and Sanderson, D. (1998). Coordinating joint design work: the role of communication and artefacts. Design Studies 19 pp 273-288

[27] Poggenpohl, S., Chayutsahakij, P., Jeamsinkul, C. (2004). Language definition and its role in developing a design discourse. In Design Studies 25(6):579-605

[28] Ravenscroft, A., Wegerif, R.B. \& Hartley, J.R. (2006). Reclaiming thinking: dialectic, dialogic and learning in the digital age, Special Issue of British Journal of Educational Psychology: Psychological Insights into the Use of New Technologies in Education (In Press) (18)
(PDF) Reclaiming thinking: Dialectic, dialogic and learning in the digital age. Available from: https://www.researchgate.net/publication/228931739_R eclaiming_thinking_Dialectic_dialogic_and_learning_i n_the_digital_age [accessed Jun 19 2019].

[29] Romeny, P. 2003. The Art of dialogue. Retrieved March 2019.

https://animatingdemocracy.org/sites/default/files/docu ments/reading room/art_of dialogue.pdf

[30] Schaik, L. V. (2014). Practical Poetics in Architecture. John Wiley \& Sons Ltd. West Sussex, United Kingdom

[31] Schön, D. A. (1984). The reflective practitioner: How professionals think in action (Vol. 5126). Basic books.

[32] Shih, Chih-ming, (2004). Between Concept and Form: Learning from Case Studies. Journal of Asian Architecture and Building Engineering vol.3 no.1 217221

[33] Smith, K. S. (2008). Architects' Sketches: Dialogue and Design. Architectural Press Elsevier, Oxford, Uk

[34] SOTIRIOS D. KOTSOPOULOS. 2006. A NOTE ON THE CONCEPTUAL BASIS OF DESIGNS. In CAADRIA 2006 [Proceedings of The 11th International Conference On Computer Aided Architectural Design Research In Asia] Kumamoto (Japan) March 30th April 2nd 2006, 585-587

[35] Suwa, M., \& Tversky, B. (1997). What do architects and students perceive in their design sketches? A protocol analysis. Design Studies, 18(4), 385-403.

[36] Tomes, A., Oates, C., \& Armstrong, P. (1998). Talking design: Negotiating the verbal-visual translation. Design Studies, 19(2), 127-42.

[37] Ulusoy, Z. (1999). To design versus to understand design: The role of graphic representations and verbal expressions. Design Studies, 20(2), 123-30. 
International Journal of Engineering Research and Technology. ISSN 0974-3154, Volume 13, Number 6 (2020), pp. 1391-1408 (C) International Research Publication House. https://dx.doi.org/10.37624/IJERT/13.6.2020.1391-1408

\section{APPENDICES}

\section{$\underline{\text { (Appendix A) }}$}

Project A Final Submission 1

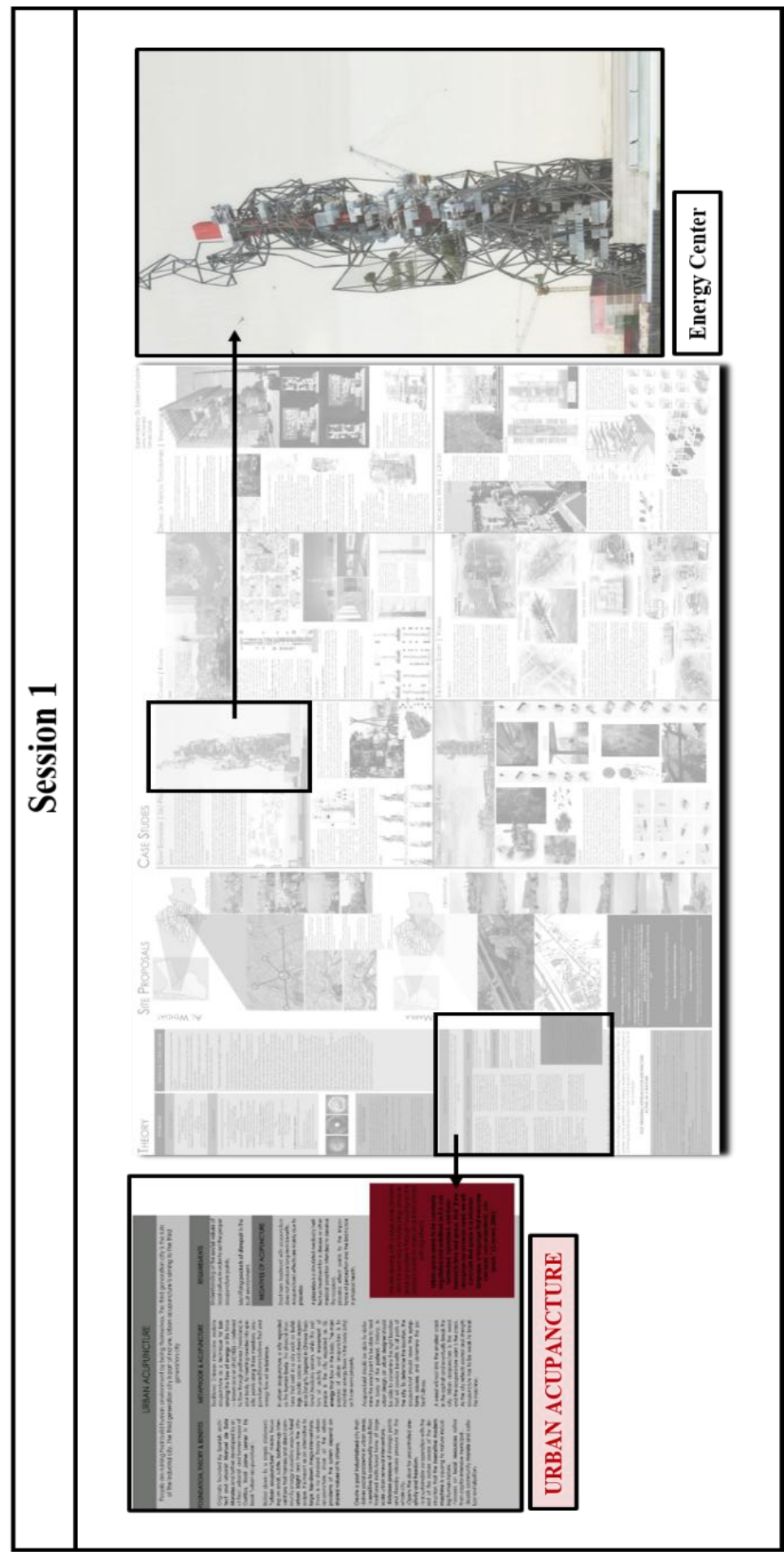


Project A Final Submission 2

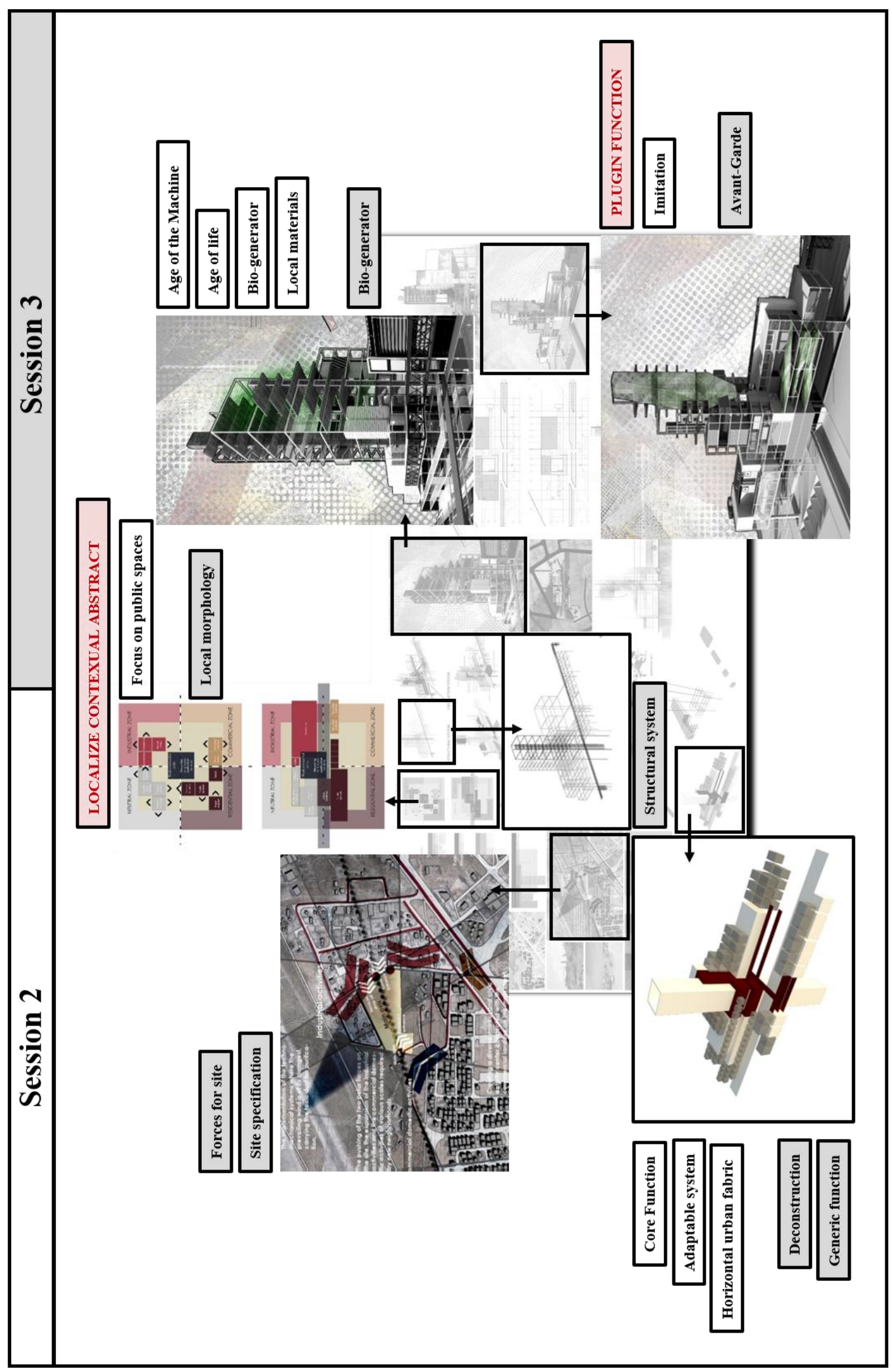


Project A Final Submission 3

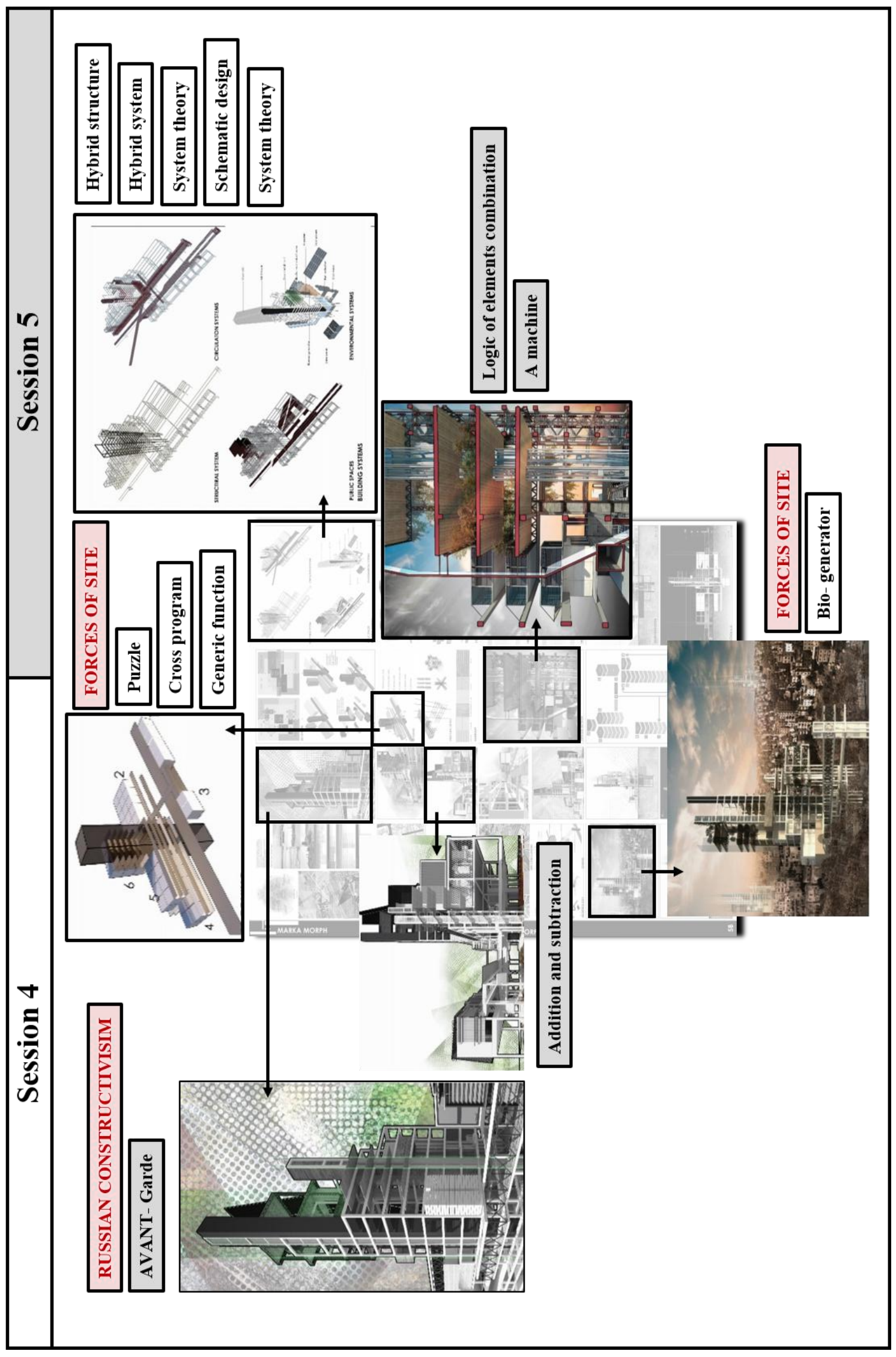


Project A Final Submission 4

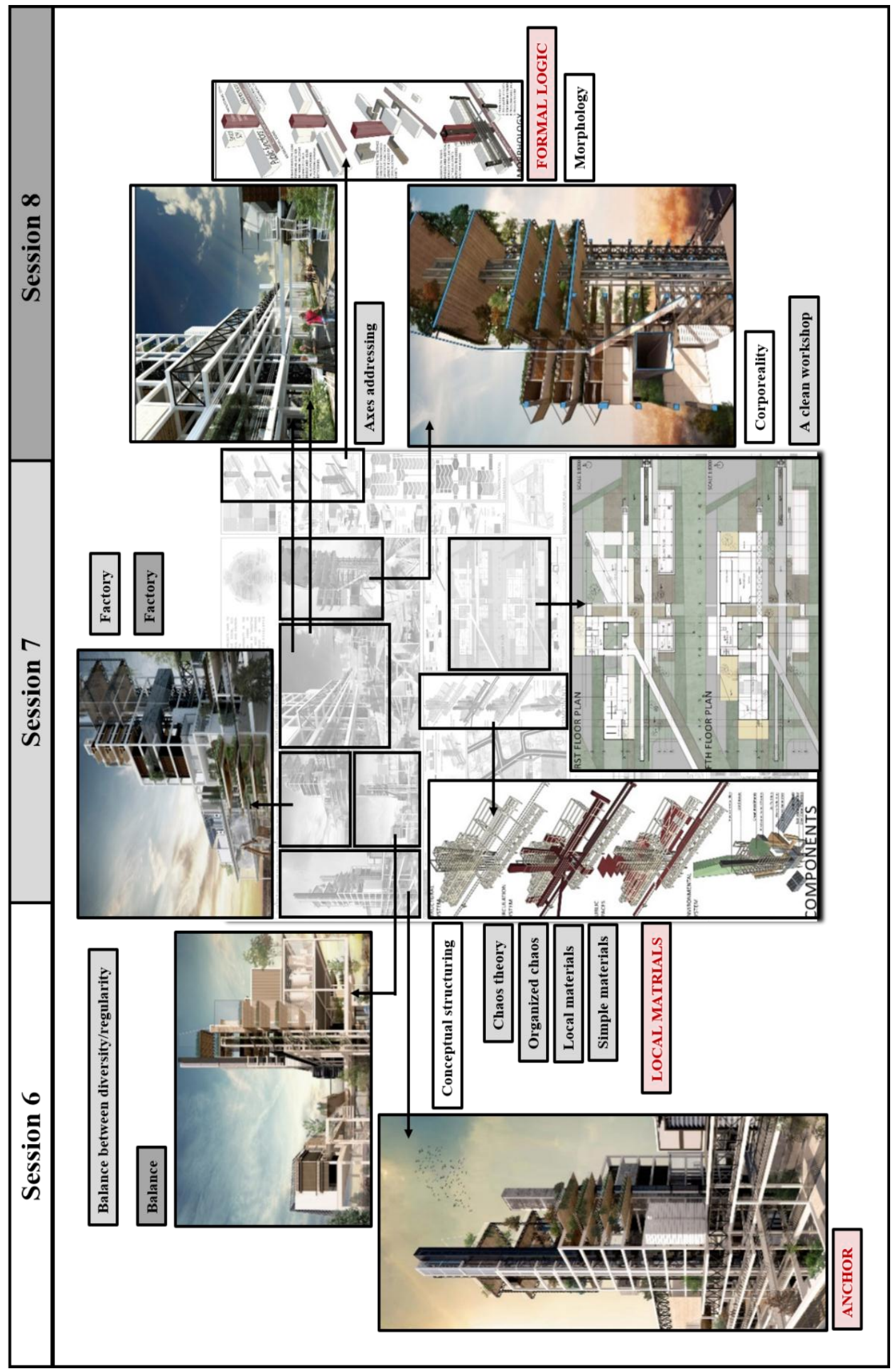


Project B Final Submission 1

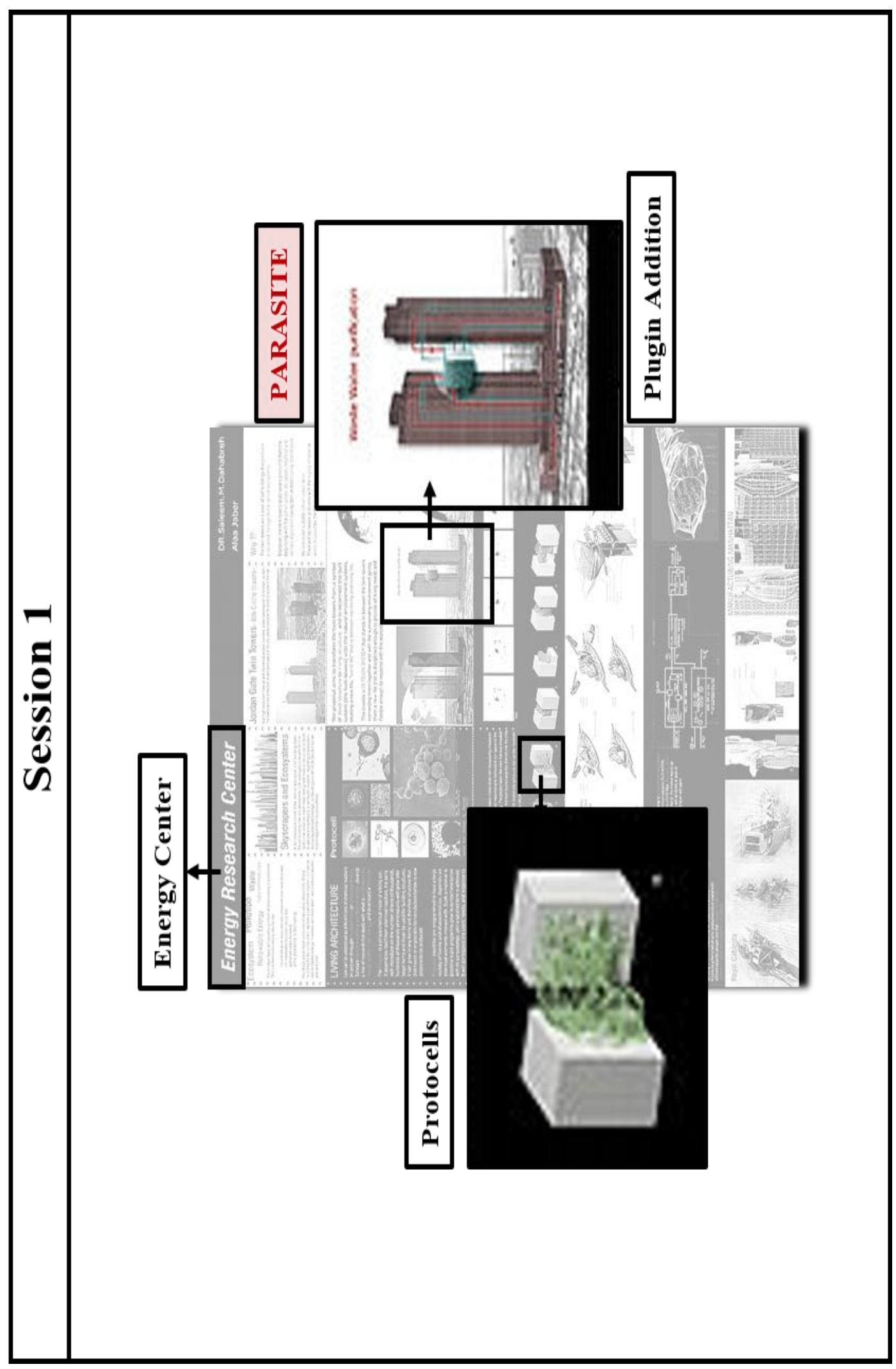


Project B Final Submission 2

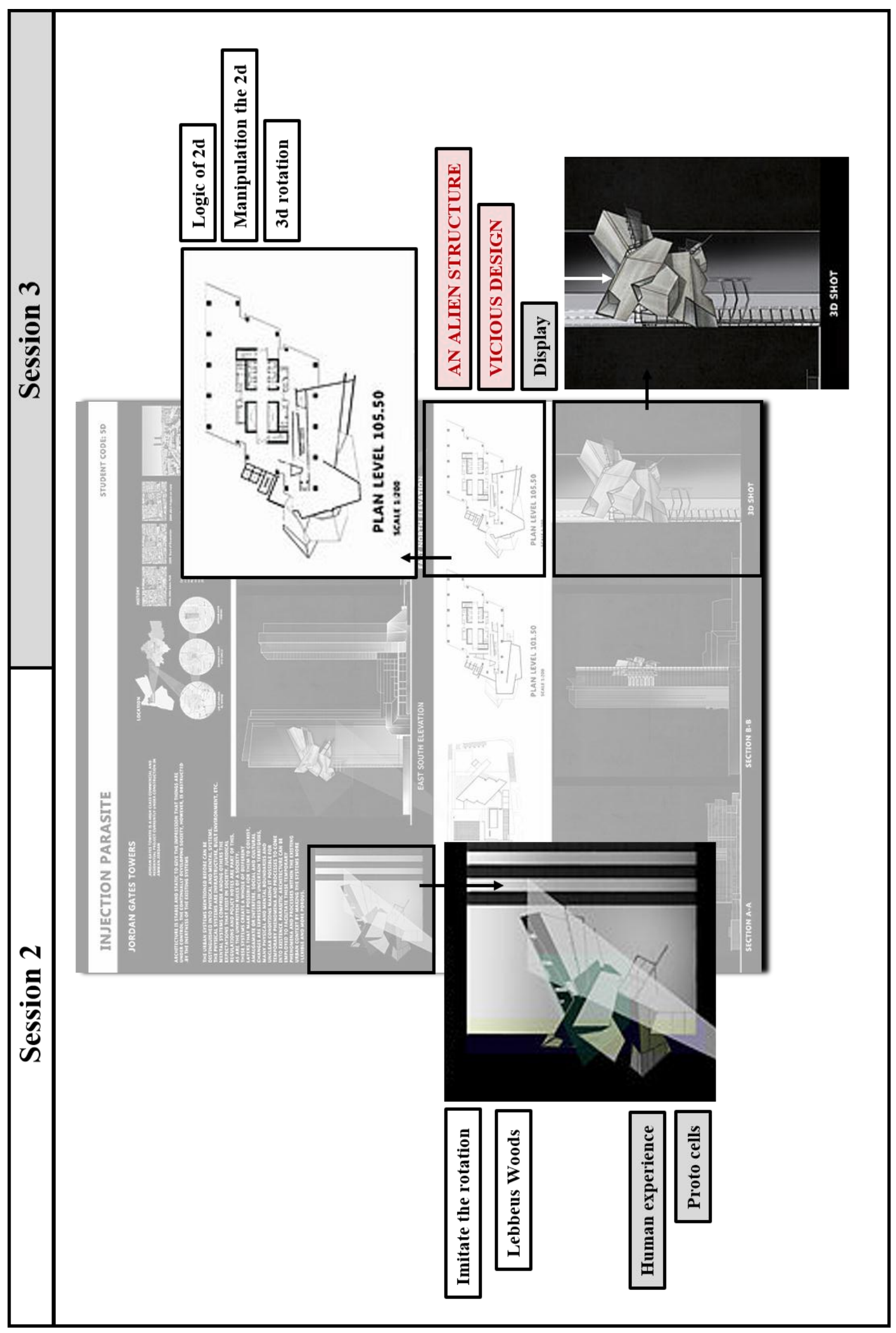


Project B Final Submission 3

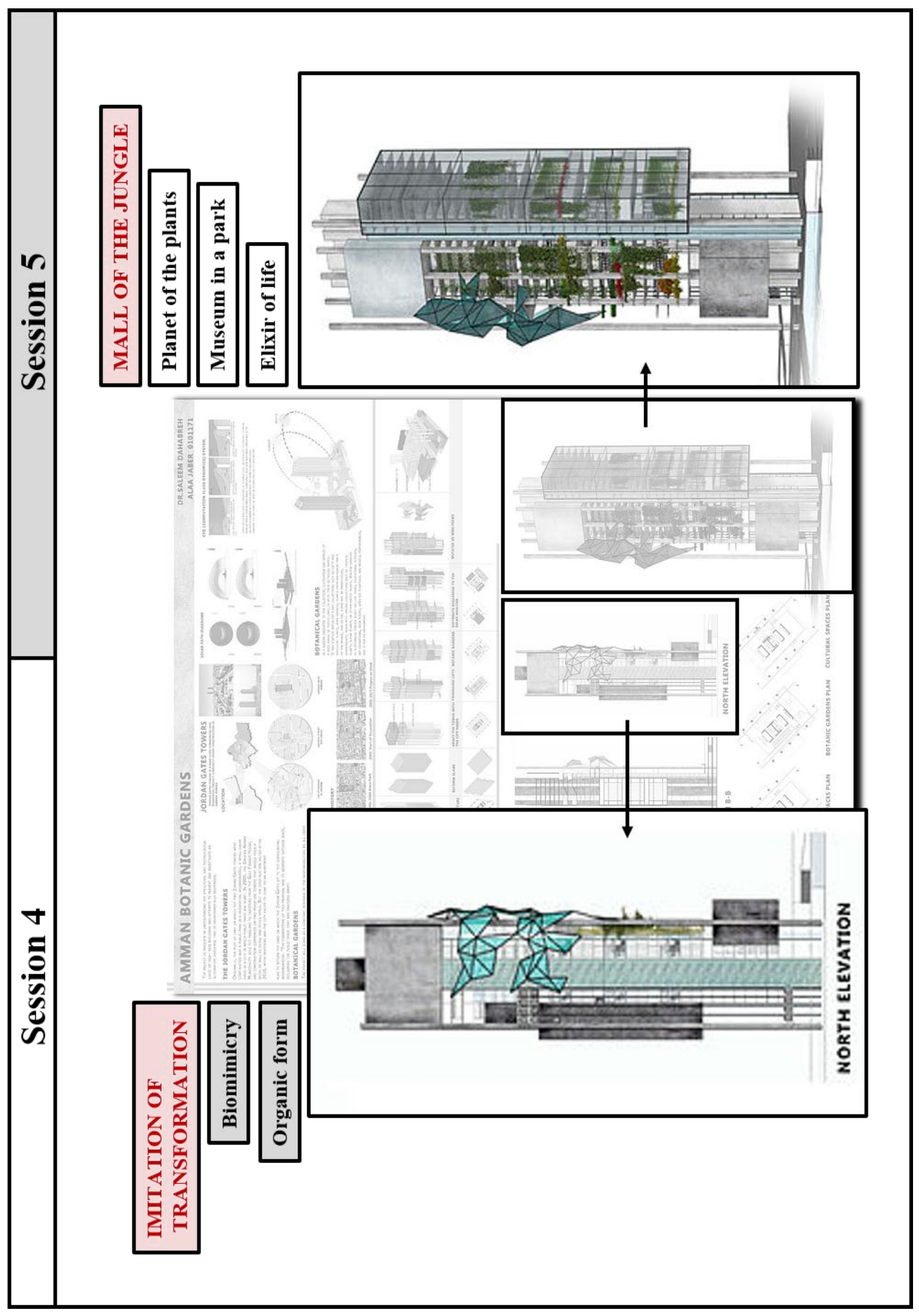


Project B Final Submission 4

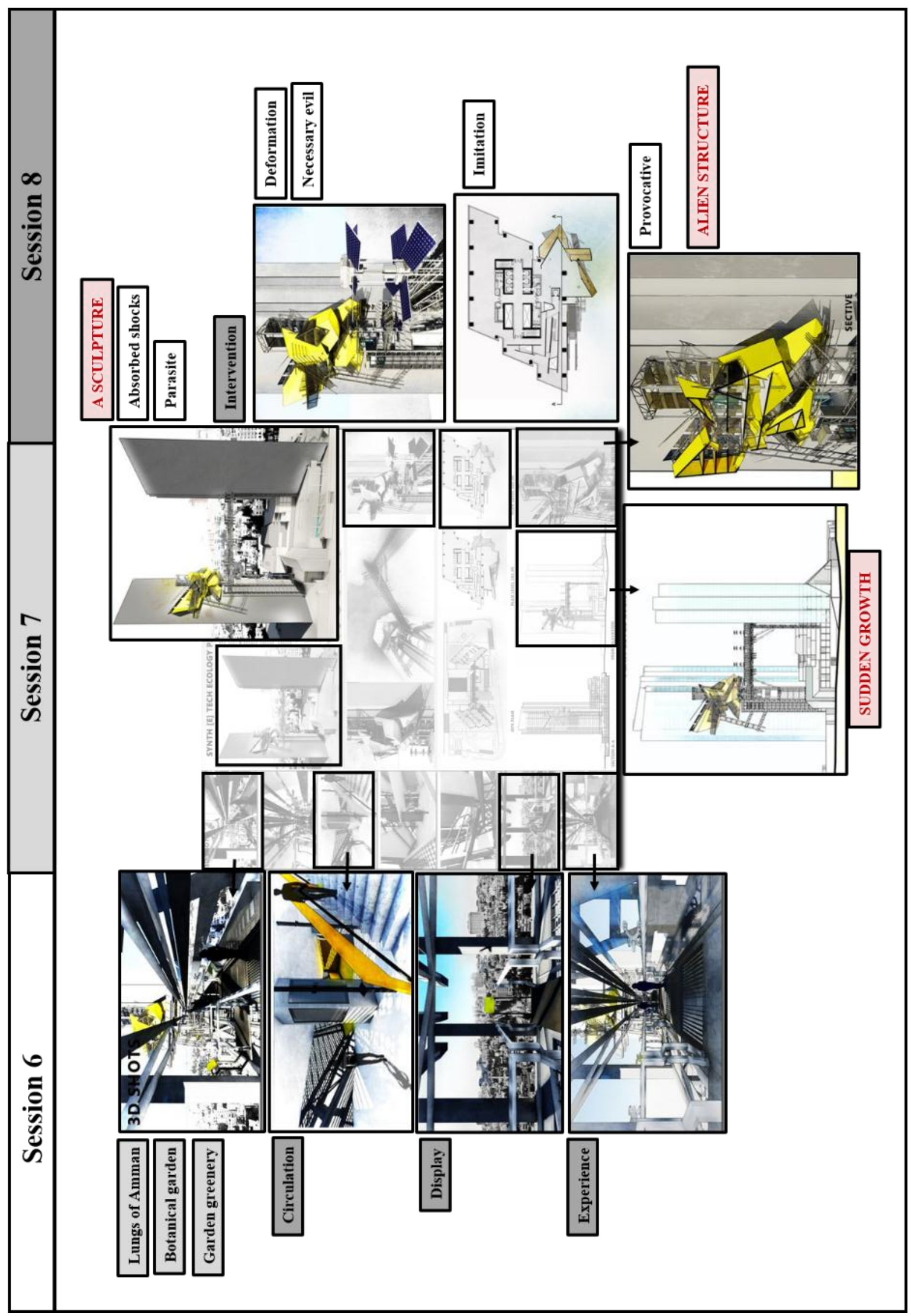

